\title{
The Usefulness Of Accounting Information, Economic Variables, And Corporate Governance Measures To Predict Corporate Failure
}

\author{
Heba S. Abou El Sood, Cairo University, Egypt
}

\begin{abstract}
This paper has the core aim of investigating the usefulness of employing accounting information, macroeconomic variables and corporate governance measures to predict corporate failure in an Egyptian setting. The empirical study is directed to adapting a corporate failure prediction model applied to a sample of Egyptian companies listed in the Egyptian stock market. A sample of 79 companies drawn from the 100 most actively traded firms listed in the Egyptian stock market has been used for the empirical testing. A pooled sample is formed covering the period 2000-2005 inclusive. The empirical study emphasized improving failure prediction accuracy by introducing two classes of variables besides financial ratios based on accounting information. These classes of variables are economic variables and corporate governance measures. Logistic regression analysis has been used to test the predictive accuracy of four models. Model I included accounting information only. Model II added economic variables to accounting information. Model III included corporate governance measures and accounting information. Finally, model IV employed these three classes of variables together. Analysis of the statistical testing results indicated that employing the three classes of variables together improved the prediction accuracy to reach $84.8 \%$ in the classification sample and $78.2 \%$ in the validation sample. Furthermore, model IV is used to predict failure up to three years prior to failure and therefore can provide a tool for failure prediction for enhancing auditing, investment and credit decisions in an Egyptian market setting.
\end{abstract}

Keywords: corporate failure prediction; accounting information; economic variables; corporate governance

\section{INTRODUCTION}

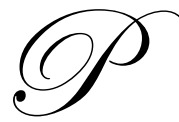

redicting the probability of corporate failure or the company's ability to continue as a going concern has been a center of attention for the academia, professionals and company stakeholders (Hassanein, 1998). The role of accounting information in predicting future performance is regarded as a core aim (Lev, 1989). Nevertheless, for more than 40 years of continuous research, few attempts have been directed to employing variables that are endogenous as well as exogenous to the firm to enhance classification and prediction accuracy of corporate failure.

Researchers have found that firms failed even though they presented fairly good financial ratios as close as two years prior to the actual failure (for example; Laitinen, 1991). Moreover, Lev (1989) argued that Generally Accepted Accounting Principles (GAAP) are regarded as biased and deficient in providing financial variables with predictive power. This argument has seriously questioned the validity and reliability of using financial information in isolation from other non-financial variables. 
This research aims at achieving the following main objective: investigating the usefulness of employing accounting information, macroeconomic variables and corporate governance measures to predict corporate failure in an Egyptian setting. This investigation is conducted with the purpose of enhancing the prediction accuracy of a model with the potential to increase the quality of investment, auditing and credit decisions.

The focus of the research is the quality of variables used -to increase prediction accuracy- rather than statistical technique utilized. It attempts to adapt a country-specific failure prediction model for companies listed in the Cairo and Alexandra Stock Exchange (CASE) and employ economic variables and corporate governance measures to enhance the predictive accuracy of a model that includes accounting ratios. The importance of corporate governance lies in its contribution to both economic prosperity and accountability. The latter has been the area of concern as well as debate not only in an Egyptian context, but also all over the world (Abou El Sood, 2005).

\section{RESEARCH METHODOLOGY}

Stemming from the main objective of this research, several steps should be undertaken to achieve that objective. First, analyzing the major directions of research on corporate failure prediction. Second, identifying explanatory variables employed in corporate failure prediction studies to determine their relative usefulness in the present study. Third, examining modeling techniques used in the literature to enhance the predictive ability of the present model. Fourth, assessing the usefulness of accounting information and corporate governance measures as well as economic variables in predicting corporate failure of listed industrial companies in Egypt. Fifth, investigating the usefulness of the combined model which includes the three classes of variables interacting in synergy for enhancing prediction accuracy of the model.

The empirical testing of the present study attempts to improve prediction accuracy of corporate failure by introducing two classes of variables besides financial ratios based on accounting information. These classes of variables are economic variables and corporate governance measures.

For empirical purposes, a model utilizing accounting information is developed (Model I). Then, economic variables only are inserted to the previous model to test for the possible incremental value of the second class of variables (Model II). Thereafter, corporate governance measures only are added to the first model to test for their usefulness (Model III). Finally, all variables -accounting information, economic variables, and corporate governance measures- are to be combined in Model IV to test for the overall predictive power of the three classes of variables combined.

The present study employs pooled data to conduct the analysis. That is; the empirical testing is conducted using cross sectional analysis across companies and through out a classification period of six consecutive years (2000-2005). The binary logistic regression analysis is used to conduct the empirical testing.

\section{Failure Specified}

Based on reviewing accounting literature, the present study employs a failure definition adapted from Hopwood et al. (1988) and Lee et al. (2003).

A company is to be considered among the failing companies if and only if one of the following conditions is fully satisfied over three consecutive years: (1) negative net operating cash flows in any of these three years, (2) net operating loss in any of the three years, and (3) negative working capital in any of the three years.

\section{Sample Composition}

The sample of the study is drawn from the 100 companies that are most actively traded in the Egyptian stock exchange. For a company to be included in the sample, the following conditions should be met: 
(1) The company's shares must have been publicly traded in the Egyptian stock exchange and classified among the 100 most actively traded firms;

(2) The company must have been classified as industrial;

(3) The company must have had at least two years of full financial statements data prior to its failure year; and

Financial institutions are excluded from the data set, since firms in such industries are structurally different and their financial reporting practices generally preclude combining them with industrial and service firms in failure prediction studies that use financial ratios (Gilbert et al., 1990; Charitou et al., 2004).

A sample of 78 observations has been randomly selected to form a hold-out or validation sample constituting exactly $24.3 \%$ of the overall sample. The sample size is restricted due to data availability considerations especially with respect to corporate governance practices that are relatively new to the Egyptian market.

The sample composition can be summarized as shown in table (1):

Table 1: Sample of Failed and Non-failed Firms

\begin{tabular}{|c|c|c|c|}
\hline \multirow{2}{*}{ Year } & Failed & Rumber of Firms & Non-failed \\
\hline 2000 & 22 & 12 & $\mathbf{5 5 \%}$ \\
\hline 2001 & 30 & 14 & $\mathbf{4 7} \%$ \\
\hline 2002 & 33 & 21 & $\mathbf{6 4} \%$ \\
\hline 2003 & 38 & 23 & $\mathbf{6 1 \%}$ \\
\hline 2004 & 42 & 17 & $\mathbf{4 0} \%$ \\
\hline 2005 & 42 & 27 & $\mathbf{6 4} \%$ \\
\hline & $\mathbf{2 0 7}$ & $\mathbf{1 1 4}$ & $\mathbf{5 5 \%}$ \\
\hline
\end{tabular}

Regarding the composition of the sample, the empirical testing is to be conducted without pairing. (Deakin, 1977; Ohlson, 1980; Gilbert et al., 1990, Boritz et al., 1995). The estimation sample consists of 243 observations that is $75.7 \%$ of the total sample- for classification purposes. Such selection is based on a 75-25 ratio for estimation and validation samples. ${ }^{(1)}$

\section{Period Of The Study}

The sample period includes six years 2000-2005 used for classification purposes.

\section{Variables Specification}

The empirical study employs three classes of variables; namely accounting information, economic variables and corporate governance measures.

Table (2) presents financial ratios that are broken down according to proxies for major categories along with a list of economic variables and corporate governance measures.

\footnotetext{
(1) The 75-25 rule was used to divide the total sample to classification and hold-out sub-samples. This means that $75 \%$ of the total observations were used as estimation sample while $25 \%$ of the total observations were employed as validation sample. Such rule is adapted from data analysis and computers II course of the University of Texas at Austin by Professor Schwab, A.
} 
Table 2: List of Variables Employed in the Present Study

(Financial ratios are broken down to major categories along with economic variables and corporate governance measures)

\begin{tabular}{|c|c|c|c|}
\hline Class & Category & No. & Variable \\
\hline \multirow{10}{*}{ 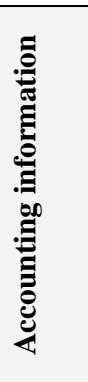 } & \multirow{3}{*}{ Financial Leverage } & 1 & Retained earnings/total assets \\
\hline & & 2 & Total liabilities/total assets \\
\hline & & 3 & Stockholders' equity/total liabilities \\
\hline & \multirow{4}{*}{ Liquidity } & 4 & Current assets/total assets \\
\hline & & 5 & Current ratio \\
\hline & & 6 & Quick assets/total assets \\
\hline & & 7 & Quick ratio \\
\hline & Profitability & 8 & Operating profit margin \\
\hline & \multirow{2}{*}{ Sales Activity/ Turnover } & 9 & Sales/current assets \\
\hline & & 10 & Sales/total assets \\
\hline \multirow{6}{*}{ 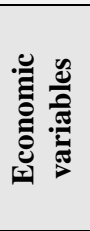 } & Annual Growth Rate of Money Supply & 11 & M2 \\
\hline & Annual Growth Rate of Real Gross Domestic Product & 12 & GDP \\
\hline & \% Annual Change in Egyptian Stock Market Index & 13 & ESMI \\
\hline & Annual Growth Rate of Consumer Price Index & 14 & CPI \\
\hline & Interest rate on industrial borrowing for a year or less & 15 & IROIB \\
\hline & Foreign exchange rate against the US dollar & 16 & EXR \\
\hline \multirow{8}{*}{ 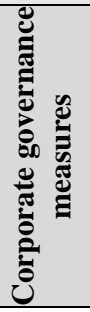 } & Board of Directors & 17 & CEO-board structure \\
\hline & \multirow{3}{*}{ Disclosure and Transparency } & 18 & Qualified audit report \\
\hline & & 19 & Remuneration of board members \\
\hline & & 20 & Risk and management policies \\
\hline & Shareholders' rights & 21 & \% block-holders \\
\hline & \multirow{3}{*}{ Stakeholders' rights } & 22 & Employee welfare \\
\hline & & 23 & Employee incentive plan \\
\hline & & 24 & Social responsibility policies \\
\hline
\end{tabular}

\section{The Statistical Technique - Logistic Regression Analysis:}

Logistic regression analysis (LRA) extends the technique of multiple regression analysis to research situations in which the outcome variable is categorical. Logistic regression describes the relationship between a dichotomous response variable and a set of independent variables. The independent variables may be continuous or discrete with dummy variables. The predictions may be made for the dichotomous outcome of success/failure (Friendly, 1995).

Logistic regression analysis does not require the restrictive assumptions regarding normality distribution of independent variables or equal dispersion matrices nor concerning the prior probabilities of failure (Ohlson, 1980; Zavgren, 1983). Rather, logistic regression is based on two assumptions; (1) it requires the dependent variable to be dichotomous, with the groups being discrete, non-overlapping and identifiable and (2) it considers the cost of type I and type II error rates in the selection of the optimal cut-off probability. However, due to the subjectivity of the choice of these misclassification costs in practice, most researchers minimize the total error rate and, hence, implicitly assume equal costs of type I and type II errors (Ohlson, 1980; Zavgren, 1985).

The equation of the present model could be expressed as:

$Z_{i}=a+\sum_{k} b_{k} X_{k, i}+\sum_{j} c_{j} E_{j, i}+\sum_{m} d_{m} G_{m, i}$

where;

$\mathrm{Z}_{\mathrm{i}}=$ the probability of failure for firm $\mathrm{i}$

and;

$\mathrm{X}_{\mathrm{k}, \mathrm{i}}=$ the $\mathrm{k}^{\text {th }}$ accounting variable of firm $\mathrm{i}$

$E_{j, i}=$ the $j^{\text {th }}$ economic variable of firm $i$

$\mathrm{G}_{\mathrm{m}, \mathrm{i}}=$ the $\mathrm{m}^{\text {th }}$ corporate governance variable of firm $\mathrm{i}$

$\mathrm{a}, \mathrm{b}_{\mathrm{k}}, \mathrm{c}_{\mathrm{j}}, \mathrm{d}_{\mathrm{m}}$ are regression coefficients 
The use of logistic regression in the present study could be justified by the following points. First, the output of the LRA, the logit score referred to as $\mathrm{Y}$ in the regression equation, is a score between zero and one, which immediately gives the probability of failure of the company rather than the score of failure as opposed to non-failure (Ohlson, 1980).

Second, the estimated coefficients in LRA can be interpreted separately as the importance or significance of each of the independent variables in the explanation of the estimated failure probability (Ohlson, 1980; Mensah, 1984; Zavgren, 1985), provided that there is no multi-collinearity among the variables. Third, logistic regression analysis allows for qualitative variables (dummies) to be used (Ohlson, 1980; Keasey and Watson, 1987).

\section{Research Hypotheses}

The present empirical study is oriented to test the following hypotheses:

$\mathbf{H}_{0 \mathrm{~A}}$ : there would be no increased prediction accuracy in a model using macroeconomic variables and accounting information compared to a model using only accounting information.

$\mathbf{H}_{0 \mathrm{~B}}$ : there would be no increased prediction accuracy in a model using corporate governance measures and accounting information compared to a model using only accounting information.

$\mathbf{H}_{0 \mathrm{C}}$ : using a model that combines the three classes of variables would not produce significant increase in prediction accuracy.

\section{EMPIRICAL TESTING}

Model I includes only accounting information. The variables selected through the stepwise method are: retained earnings/total assets, total liabilities/ total assets, equity-to-debt ratio, current assets/total assets, current ratio, and operating profit margin. The coefficients in the four models can be viewed in table (3).

Model II incorporates macroeconomic variables. Nonetheless, only the consumer price index variable is selected in the final model iteration with a positive coefficient of 5.687. That could be attributed to the fact that economic variables in general affect the financial performance of all sample firms alike, therefore, not having a significant value to the predictive power of the model. Model III adds corporate governance measures only to accounting information. The model reveals that joint CEO-board structure has a negative coefficient indicating that higher probability of failure is associated with lower joint CEO-board structures. Analysis results have been contrary to the research expectation as well as the results of previous studies.

Such results could be attributed to the fact that most of the sample companies (77\% of healthy firms and $55 \%$ of failing firms) have joint CEO-board structures; which might seem a country-specific attribute affecting the sample of Egyptian firms. Nonetheless, it can be beneficial not to embrace the efficient ownership structure of anonymous small diversified shareholders common to the US, UK and "economic theory". According to Dyck (2000), when legal protections are ineffective, ownership concentration can provide the functions of a corporate governance system and enhance promise fulfillment. Bebchuk (1999) points out that ownership concentration may be more efficient than efforts to introduce disperse shareholding. 
Table 3: Coefficients of the binary logistic regression models

\begin{tabular}{|c|c|c|c|c|}
\hline & Model I * & Model II ** & Model III † & Model IV $\uparrow \dagger$ \\
\hline Constant & 0.457 & & 0.457 & 0.520 \\
\hline RETA & -8.240 & -8.316 & -8.240 & -9.052 \\
\hline TLTA & 4.131 & 4.552 & 4.131 & 4.615 \\
\hline SETL & -0.053 & -0.052 & -0.053 & -0.050 \\
\hline CACL & 0.442 & 0.391 & 0.442 & 0.380 \\
\hline QATA & -4.609 & -4.360 & -4.609 & -4.239 \\
\hline OPM & -3.354 & -3.246 & -3.354 & -3.546 \\
\hline CPI & & & & 5.687 \\
\hline CEOB & & & -0.933 & -0.955 \\
\hline
\end{tabular}

* Model I includes accounting variables

** Model II includes accounting and economic variables

$\uparrow$ Model III includes accounting and corporate governance variables

$\dagger$ Model IV includes accounting, economic and corporate governance variables

Finally, model IV combines the three classes of variables. The final selected variables and related regression coefficients as shown in table (3) are used to derive the logistic regression equation:

$$
\begin{aligned}
& \mathrm{Z}_{\mathrm{i}}=\quad 0.520-9.052 \text { RETA }+4.615 T L T A-0.050 S E T L+0.380 C A C L \\
& \text { - 4.239 QATA - 3.546 OPM + 5.687 CPI - 0.955 CEOB } \\
& \begin{array}{llll}
(0.000) & (0.000) & (0.105) & (0.014)
\end{array} \\
& \text { * significance (p-value) }
\end{aligned}
$$

Regarding economic variables, the model includes annual growth rate of consumer price index (CPI) which has a positive coefficient. This result might be due to the effect of inflation on companies' borrowing. Companies are obligated to pay their financial obligation with interest according to the inflationary conditions, which raises question regarding companies' probability to default. With respect to corporate governance measures, CEO-board structure remains important in predicting company failure. This result might be due to the concentrated ownership in which the board member is also a major shareholder. This structure might seem contrary to other governance structures in other countries like USA and the UK. It seems interesting to know how the integration among the three classes of variables increased the predictive power of the failure prediction model. General economic conditions alone might not seem valuable in enhancing predictive accuracy, as they have a uniform effect on all firms. However, when affecting company endogenous characteristics, such macroeconomic indicators become more meaningful and more value-adding.

\section{Tests Of Goodness Of Fit}

\begin{tabular}{|c|c|c|c|c|}
\hline Model & -2 log likelihood & Cox \& Snell $\mathbf{R}^{2}$ & Nagelkerke $\mathbf{R}^{2}$ & Hosmer \& Lemeshow test \\
\hline $\mathrm{I}$ & 224.633 & 0.333 & 0.454 & 8.092 \\
\hline II & 221.764 & 0.341 & 0.465 & 23.129 \\
\hline III & 218.476 & 0.349 & 0.477 & 8.594 \\
\hline IV & 215.273 & 0.358 & 0.488 & 14.703 \\
\hline
\end{tabular}

It could be noticed from table (4) that combining the three classes of variable in model IV improves the log likelihood, Cox \& Shell $\left(\mathrm{R}^{2}\right)$, Nagelkerke $\left(\mathrm{R}^{2}\right)$ and Hosmer \& Lemeshow test compared to other models.

Table 4: Results of the Tests of Goodness of Fit 


\section{Classification Accuracy}

The classification and prediction accuracy of the four models is assessed and summarized in table (5).

Table 5: Classification and Prediction Accuracy of the Fitted Models - One Year Prior to Failure

\begin{tabular}{|c|c|c|c|}
\hline Model & Firms & Classification Accuracy & Prediction Accuracy \\
\hline \multirow{3}{*}{ I } & Failing & $65.6 \%$ & $58.3 \%$ \\
\hline & Healthy & $88.2 \%$ & $77.8 \%$ \\
\hline & Entire Sample & $79.8 \%$ & $71.8 \%$ \\
\hline \multirow{3}{*}{ II } & Failing & $65.6 \%$ & $58.3 \%$ \\
\hline & Healthy & $88.2 \%$ & $77.8 \%$ \\
\hline & Entire Sample & $79.8 \%$ & $71.8 \%$ \\
\hline \multirow{3}{*}{ III } & Failing & $71.1 \%$ & $75 \%$ \\
\hline & Healthy & $91.5 \%$ & $77.8 \%$ \\
\hline & Entire Sample & $84 \%$ & $76.8 \%$ \\
\hline \multirow{3}{*}{ IV } & Failing & $71.1 \%$ & $70.8 \%$ \\
\hline & Healthy & $92.8 \%$ & $81.5 \%$ \\
\hline & Entire Sample & $84.8 \%$ & $78.2 \%$ \\
\hline
\end{tabular}

\section{Out-Of-Sample Validation Of The Model}

Validation tests examine the ability of the estimation model to predict failure of a new set of observations. Testing of hypotheses is conducted through the z-statistic as the sample is large enough to support its use. With respect to difference in proportions of model I and model II, since $\mathrm{P}_{1}=\mathrm{P}_{2}$, then, the first null hypothesis is accepted, i.e. the addition of economic indicators to the accounting information would not enhance the accuracy of predication as stated in the first hypothesis "there would be no increased prediction accuracy in a model using both macroeconomic variables and accounting information compared to a model using only accounting information".

Similarly, when calculating the difference in proportions for model I and model III, results indicate a pvalue of 0.0708 which means that model III is marginally significant. Therefore, the second null hypothesis $H_{0 B}$ which states that "there would be no increased prediction accuracy in a model using both corporate governance measures and accounting information compared to a model using only accounting information" could be rejected.

Regarding difference in proportions for model I and model IV, the z-statistic equals 1.88 which corresponds to a level of significance of 0.031 . Hence, there seems to be an appropriate ground on which to reject the third null hypothesis $H_{O C}$ which states that "using a model that combines the three classes of variables would not produce significant increase in prediction accuracy". It could be concluded that integrating accounting information, economic variables, and corporate governance measures improves the prediction accuracy for the sample firms.

\section{Testing Multicollinearity And Examination Of Residuals}

Multicollinearity diagnostics reveal no dependency among predictor variables. Results can also be matched against by Pearson's correlation coefficients. Examination of residuals does not indicate a reason for concern. Moreover, most cases of the sample have standardized value of less than \pm 2.5 . Few cases, i.e. sample firms, have absolute values of more than 2; however such cases do not exceed $5 \%$ of the sample firms. Therefore, it could be said that the model is a good representation of the actual data.

\section{Robustness Of The Model}

To test the robustness of the three-class-variables model, prediction results were generated for up to 5 years prior to the event of failure based on a circular sample. A summary of results is presented in table (6). 
Table 6: Model Robustness -Testing for Several Years Prior to Failure

\begin{tabular}{|c|c|c|}
\hline Years Prior to Failure & No. of firms in the sample & Percentage Correct \\
\hline 1 year & 79 & $78.2 \%$ \\
\hline 2 years & 61 & $73.7 \%$ \\
\hline 3 years & 54 & $70 \%$ \\
\hline 4 years & 44 & $66.7 \%$ \\
\hline 5 years & 34 & $66.7 \%$ \\
\hline
\end{tabular}

Results indicate that the model is robust and valuable results could be obtained for up to five years prior to failure. However, predictive power decreases as the time lag increases, this might be due to losing the predictive ability of the independent variables as the time lag increases between the information used in the analysis and the event of failure. Such results might prove valuable for various interested parties.

The model could be used by auditors to estimate the probability of failure -and hence audit risk- for client firms one year prior to failure. Estimating probability of failure for up to 3 years could seem valuable for credit rating agencies and financial institutions considering granting loans to companies. Furthermore, investment decisions in listed companies could be enhanced through predicting failure for up to 3 years prior to failure.

\section{CONCLUSION}

A three-class-variable model proves superior in predicting corporate failure among the sample firms - at the 5\% level. The final model stresses the importance of leverage and liquidity as important factors in predicting failure. Integrating the three classes of variables together in one model produces a relatively high prediction accuracy, which has been hypothesized.

Concerning macroeconomic factors, inflation - as reflected in percentage change in consumer price indexproved significant. The effect of increasing inflation and the financial burden on a firm might be a reason for such a firm to experience failure.

The final composite model includes the existence of a CEO-board structure as a significant corporate governance measure used in failure prediction. Such variable is negatively associated with failure. The negative association could be explained as follows: the CEO who is also setting as a chairman for the board of directors might be a deterrent to high probability of failure. This result has been contradictory to good corporate governance guidelines. Therefore, such element seems worthy of being studied thoroughly as a country-specific indicator of corporate governance practices.

\section{FURTHER RESEARCH}

The present study emphasizes the usefulness of incorporating other non-accounting information to models containing accounting information with the core aim of enhancing corporate failure prediction. Future research work in the arena of predicting corporate failure could be directed in two main streams:

A. Focusing on the enhancement of prediction accuracy of the model by relaxation of underlying assumptions and sampling characteristics.

B. Improving prediction through utilizing other explanatory variables that are environment-specific and conceptually well-furnished.

Further research efforts would be needed to cover these points:

1. Macroeconomic variables affect companies uniformly. Hence, it seems important to study the effect of macroeconomic indicators - over a time series- on companies' probability of failure. The time series might 
encompass an economic cycle with booming and recessionary conditions. Therefore, it may seem necessary to account for the problem of non-stationarity of data in longer time series.

2. The conformity to good corporate governance practices seems vital in failure prediction. However, measures selected in the model of the present study are based on country-specifics. Therefore, when developing such a model in other environments, adaptation to the local settings seems essential. Making good use of local corporate governance guides in choosing which measures to include in the model seems invaluable in reflecting country-specific practices.

3. Defining corporate failure instead of identifying bankrupt firms might provide early warning signals to interested parties when using failure prediction models. The bankruptcy event seems to be happening as a final stage after failure signs take place.

4. Further investigation is needed regarding the effect of the statistical technique used in failure prediction. Comparing results when using logistic regression to other methods seems worthy of examination.

5. Adapting the prediction model to industry, size, and age of companies seems important. Therefore, further studies would seem to be needed to generate more specific results that might be useful for investment, financing and auditing decisions for such companies.

6. Incorporating misclassification costs into the model might be another interesting area for investigation. Such analysis might enhance user-specific decisions.

7. Further research can provide useful results concerning other market settings comparable to the Egyptian setting. Countries furnishing good corporate governance practices might provide interesting comparison. In-depth analysis of results might shed light on policy recommendations.

\section{REFRENECES}

1. Abou El Sood, H. (2005). The Enhancement of Participatory Climate for Corporate Governance in Egypt Towards Integration with Global Initiatives. Proceedings of the $5^{\text {th }}$ Annual Conference on Corporate Governance and its Accounting, Economic and Management Dimensions, Faculty of Commerce, Alexandria University, Egypt.

2. Charitou, A., Neophytou, E. and Charalambous, C., (2004). Predicting Corporate Failure: Empirical Evidence for the UK. European Accounting Review, 13 (3), 465-497.

3. Gilbert, L., Menon, K. and Schwartz, K. (1990). Predicting Bankruptcy for Firms in Financial Distress. Journal of Business, Finance and Accounting, 17 (1), 161-171.

4. Hassanein, T. (1998). Measuring the Ability of Cash Flows to Predict the Going Concern Using Artificial Neural Networks. The Scientific Journal for Research and Commercial Studies, Helwan University, (3/4), 289-333 (in Arabic).

5. Hopwood, W., Mckeown, J. and Mutchler, J. (1988). The Sensitivity of Financial Distress Prediction Models to Departures from Normality. Contemporary Accounting Research, 5 (1), 284-298.

6. Lee, T., Yeh, Y. and Liu R. (2003). Can Corporate Governance Variables Enhance the Prediction Power of Accounting-Based Financial Distress Prediction Models. Working Paper No.2003-14, Institute of Economic Research, Hitotsubashi University.

7. Lev, B. (1989). On the Usefulness of Earnings and Earnings Research: Lessons and Directions from Two Decades of Empirical Research. Journal of Accounting Research, Supplement, 27, 153-191.

8. Ohlson, J. (1980). Financial Ratios and the Probabilistic Prediction of Bankruptcy. Journal of Accounting Research, 18 (1), 109-131.

9. Zavgren, C. (1985). Assessing the Vulnerability to Failure of American Industrial Firms: A Logistic Analysis, Journal of Business Finance and Accounting, 12 (1), 19-45. 


\section{NOTES}

